\title{
Efficiency of the green bond market and its role in regional security
}

\author{
Valentina Karginova-Gubinova ${ }^{1, *}$, Anton Shcherbak ${ }^{1}$, and Sergey Tishkov ${ }^{1}$ \\ ${ }^{1}$ Institute of Economics of the Karelian Research Centre of the RAS, 50 Al. Nevsky Prospect, \\ Petrozavodsk, 185030, Russia
}

\begin{abstract}
Financing capital-intensive projects in the green economy is possible through green bonds. The assessment of the economic efficiency of the green bond market, the determination of its role in ensuring the energy and economic security of the regions and the development of directions and instruments for improving the efficiency and significance of the market for the Russian Federation are the aim of the study. The methodology involved the determination of the autocorrelation presence in the calendar series of bond yields using the Broysch-Godfrey LM test, the application of applied statistics methods to verify the existence of calendar effects on the stock exchange and analyze market reviews. Data on the green bond market were compared with data on other bonds. Market performance calculations were based on the S\&P Green Bond Index and S\&P 500 Bond Index. Features and benefits of green bonds as an instrument to ensure regional security were identified. The lack of market efficiency for green and other bonds, even in a weak form, was shown. The necessary institutional changes to improve the efficiency of the green bond market and develop it in the Russian Federation have been proposed. The findings are of theoretical importance, complementing the work on testing the hypothesis of an effective market, and of practical importance in the form of recommendations for on market improving.
\end{abstract}

\section{Introduction}

\subsection{Problem Statement}

Ensuring the security of regions implies achieving their sustainable economic development and leveling existing environmental risks, improving the quality of the environment. This is possible due to the development of the green economy: the construction of power plants on renewable energy sources, the spread of low-carbon transport, etc. However, most of the projects in the field of green economy require significant capital investments.

The required initial capital in full is not available for most potential investors. They often cannot get the missing amount from the bank because, for example, they do not have collateral. Or investors are offered a loan at such a high rate that it cannot be covered due to the profitability of the power plant.

\footnotetext{
*Corresponding author: vkarginowa@yandex.ru
} 
Green bond loans can be considered in this case as an alternative to bank loans.

A single approach to the concept of green bonds does not exist at present, however, most issuers adhere to the «Green Bonds Principles», which were established by the International Capital Market Association [1].

In accordance with these principles, green bonds are debt instruments that involve the allocation of proceeds from the placement exclusively for partial or full financing or refinancing of new or existing green projects, which is confirmed by a special external assessment and disclosure of financial statements. Projects can cover a wide range of areas, for example, renewable energy and energy efficiency, pollution prevention and control, biodiversity conservation, clean transport, sustainable water and wastewater management, climate change adaptation and others. The criteria for assigning projects to green may be different in different sectors and regions [1].

The first issuer of green bonds was the European Investment Bank in 2007. These bonds were formerly called climate protection bonds. The name «green bonds» was fixed a little later, a year later, when the International Bank for Reconstruction and Development issued them under this name. Debt instruments were previously used to finance projects in the field of ecology, but these instruments did not provide an indication of the environmental spending money goals. 628 issuers issued green bonds from 2007 to 2018 [2].

Assessing the economic efficiency of the green bond market, determining its role in ensuring the energy and economic security of the regions and developing directions and instruments to increase the efficiency and importance of the market for the Russian Federation are the goal of this work.

\subsection{Literature review}

Eugene Fama formulated an efficient market hypothesis in 1970 [3]. In accordance with this hypothesis, the prices of financial assets are completely determined by the available information [4] and, therefore, coincide with the investment value of securities. Therefore, asset purchase and sale transactions can be considered fair [5]. Accordingly, an investor can make a big profit only if he agrees to a greater risk in the framework of the efficient market hypothesis.

E. Fama identified three forms of market efficiency:

- weak - all information contained in past price changes is reflected in current changes;

- moderate - past dynamics and other publicly available information are contained in prices; [3].

- strong - insider information, along with publicly available data, is reflected in prices

Currently, the number of investors and financial analysts involved in securities transactions and monitoring all data on them significantly exceeds the number of assets traded. This suggests that the information is fully reflected in transaction prices. However, the high cost of data and access to it by various market participants at different times cast doubt on the efficient market hypothesis.

In addition, it should be borne in mind that empirical data do not confirm the rationality of investor behavior, their exclusive orientation to future income. Investors may succumb to herd instinct, draw incorrect conclusions about losses or gains [4], as well as loss aversion or overconfidence are characteristic of many investors [6].

The irrationality of investors in practice can be illustrated with the help of calendar effects - abnormal changes in the yield of securities characteristic of a certain time, day of the week, month, etc. [4]. 
The conclusion was made about the significant prevalence of calendar effects in the middle of the last century and their disappearance from the 1980s based on an analysis of the US stock market by the Dow Jones Industrial Average from 1900 to 2018 [7]. At the same time, it was shown that calendar effects were observed on the New York Stock Exchange from 1998 to 2008 for a certain group of firms [8].

The «Friday effect» («the end of the week effect»), which is reflected in the higher yield on Friday compared to other days, was confirmed by the example of Indonesia, Malaysia [9], Kenya [10] and Romania [11]. At the same time, this effect is absent in Singapore [9] and Ghana [10].

An analysis of 28 indices for 25 developed and developing countries showed that calendar effects for different markets appear on different days, and a calendar effect is observed on each working day of the week for at least two of the considered indices [12]. The «Monday effect» is typical for most countries - lower profitability on Monday compared to other days of the week. However, Tuesday rather than Monday is the most negative day, for example, in the Tunisian market [13].

The effect of Ramadan is observed in Muslim countries, an increase in profitability and a decrease in volatility occurs this month. Also, the January effect is characteristic of Muslim countries - the largest growth of quotations during the year in January. A large increase in profitability in most countries is observed if Ramadan coincides with January [14].

French government bond market was the basis of the first information efficient market model. Despite this, the effectiveness of stock markets has been studied quite well, but much less research has been devoted to the effectiveness of bond markets. The calculation of the effectiveness of thirty bond indices of both developed and developing countries was made in one of the works [15], based on which a rating of sovereign bond markets was compiled. The markets of individual countries, for example, India and China, were also analyzed [16].

A comprehensive analysis of the performance of the green bond market was not performed, however, its individual characteristics were investigated.

A distinction between private and institutional green bonds was noted: the first are less liquid and more volatile, but their yield is greater - and often it exceeds the yield of other, not green bonds [17].

The conclusion about the lower yield of green bonds compared to ordinary bonds was made from July 2013 to December 2017 and, accordingly, the low impact of environmental preferences of investors on bond prices [18]. On the other hand, given the higher concentration of green bonds among investors, it can be said that some of them are ready to sacrifice profitability for environmental purposes [19].

In addition, we note a higher demand for green bonds and, accordingly, the size of the issue with a large coupon rate, credit rating and financial condition of the issuer, as well as with collateral. Euro bond issuance, focus on international markets matters to developing countries [20].

Green bond prices strongly correlate with corporate and treasury bond prices and weakly correlate with stock and energy commodity market asset prices. You could even say that corporate and treasury bond prices affect the prices of green bonds, but not the asset prices of stock and energy commodity markets. Accordingly, green bonds are a poor instrument to diversify risks for investors in corporate and treasury bonds, but they are of significant interest to those who invest in the stock and energy commodity markets [21]. 


\section{Materials and methods}

The state of the global and Russian green bonds market was analyzed using applied statistics methods based on reviews of relevant markets.

The assessment of effectiveness of the market in terms of the completeness of the information displayed in prices was carried out on the basis of determining the presence of autocorrelation in the time series of the yield of green bonds. Autocorrelation on the stock exchange indicates the existence of a certain trend, expressed in the dependence of the price level of future periods on past periods. This indicates a lack of market efficiency, even in a weak form.

The Broysch-Godfrey LM test was selected to determine the presence of autocorrelation, which is due to the wide possibility of its application, in contrast, for example, from the more well-known Darbin-Watson criterion. We note that the last criterion gives correct results only with a normal distribution of random errors and only for a first-order autoregressive process.

The irrationality of the subjects and, consequently, the inefficiency of the markets were additionally checked by determining the presence of calendar effects on the market. «Day of the week effect» («Monday effect»), «end of week effect» («Friday effect») and «January effect» were selected. The presence of the first two of the above effects was checked by calculating the ratio of the average change in the green bond index during each day of the week to the average daily change in the index for the period, as well as the fraction of days during which the index decreased and increased. Checking for the existence of the «January effect» involved calculating the monthly growth of the index and January rank among all months for each year.

The S\&P Green Bond Index was selected as the green bond index, which includes corporate, state and interstate bonds, the proceeds of which are used to finance environmentally friendly projects. Calculations were also made using the S\&P 500 Bond Index, an index of corporate bonds of companies included in the S\&P 500, to compare the results with other non-green bonds.

Considering that green bonds should undergo an external independent evaluation, and information on the use of collected funds should be publicly available, it can be assumed that the green bond market should be more effective than others.

The S\&P Green Bond Index was launched on July 31, 2014, the S\&P 500 Bond Index was launched on July 8,2015 . The calculations cover the period from the date of launch to the end of 2018 .

\section{Results}

\subsection{Development dynamics and current state of the green bond market}

The total amount of green bond issues in the world amounted to $\$ 522$ billion from 2007 to 2018 , and emissions were made by organizations and authorities from 54 countries.

The largest total size of green bonds was issued by European countries, followed by North America and the Asia-Pacific region. The countries of the Asia-Pacific region are ahead of European countries in the number of issuers: 222 against 193.

The U.S. issued green bonds for the largest total amount (\$34 billion, 20\% of the total market) in 2018. China has smaller indicators: total emissions - $\$ 31$ billion, market share 18\%. Mortgage Agency Federal National Mortgage Association (Fannie Mae) (USA) takes first place among companies [2]. 
«Resursosberegeniye KMAO» LLC became the first issuer of green bonds in the Russian Federation on December 19, 2018. Bonds worth 1.1 billion rubles placed for 12.5 years, yield on placement $-9.76 \%$. The money received was used to build and operate a solid municipal waste landfill in Nefteyugansk district. The first issue of green Eurobonds belongs to «Russian Railways» OJSC (May 2019, bonds worth 500 million euros for 8 years).

The sustainable development sector appeared on the Moscow Exchange in 2019, focused on three types of bonds: green, social and socially significant projects. The debt security to be included in the green bond segment must comply with the «Green Bonds Principles» of the International Capital Market Association or similar principles of the «Climate Bonds Initiative», a non-profit organization. Independent external evaluation acts as a confirmation of compliance [22].

Green bonds of only two issuers were introduced into the sustainable development sector of the Moscow Exchange at the end of 2019: PJSC CB Center-invest and FPK Garant-invest, bidding dates - November 15, 2019 and December 17, 2019, respectively. Thus, the sector is still in its infancy.

Issues of some other Russian issuers also provide for the financing of environmental projects (for example, concessions in the field of public utilities or transport), however, these securities were not marked as green [22]. The reason for this could be low awareness of the features and benefits of the new type of bond loans and the need to pay an independent external evaluation for marking bonds.

\subsection{Green Bond Market Efficiency}

LM statistics based on daily growth rates of the S\&P Green Bond Index and S\&P 500 Bond Index are calculated to assess the Green Bond Market Efficiency in 2014-2018. Next, autoregressive dependences of the residues from their previous values are considered based on a third-order model.

The results are presented in tables 1 and 2 .

Table 1. LM statistics based on daily growth rates of the S\&P Green Bond Index in 2014-2018

\begin{tabular}{|c|c|c|c|c|c|}
\hline Month & 2014 & 2015 & 2016 & 2017 & 2018 \\
\hline 1 & $\mathrm{n} / \mathrm{a}$ & 18.00 & 17.00 & 19.00 & 19.00 \\
\hline 2 & $\mathrm{n} / \mathrm{a}$ & 17.00 & 18.00 & 17.00 & 17.00 \\
\hline 3 & $\mathrm{n} / \mathrm{a}$ & 19.00 & 20.00 & 20.00 & 19.00 \\
\hline 4 & $\mathrm{n} / \mathrm{a}$ & 19.00 & 18.00 & 17.00 & 18.00 \\
\hline 5 & $\mathrm{n} / \mathrm{a}$ & 18.00 & 19.00 & 20.00 & 20.00 \\
\hline 6 & $\mathrm{n} / \mathrm{a}$ & 19.00 & 19.00 & 18.00 & 18.00 \\
\hline 7 & 20.00 & 20.00 & 18.00 & 18.00 & 19.00 \\
\hline 8 & 18.00 & 18.00 & 20.00 & 20.00 & 20.00 \\
\hline 9 & 19.00 & 19.00 & 19.00 & 18.00 & 17.00 \\
\hline 10 & 20.00 & 19.00 & 18.00 & 19.00 & 20.00 \\
\hline 11 & 17.00 & 18.00 & 19.00 & 19.00 & 19.00 \\
\hline 12 & 20.00 & 18.00 & 19.00 & 17.00 & 17.00 \\
\hline Minimum & 17.00 & 17.00 & 17.00 & 17.00 & 17.00 \\
\hline Maximum & 20.00 & 20.00 & 20.00 & 20.00 & 20.00 \\
\hline Average & 19.00 & 18.50 & 18.67 & 18.50 & 18.58 \\
\hline
\end{tabular}

Source: calculated by the authors. 
Table 2. LM statistics based on daily growth rates of the S\&P 500 Bond Index in 2015-2018

\begin{tabular}{|c|c|c|c|c|}
\hline Month & 2015 & 2016 & 2017 & 2018 \\
\hline 1 & $\mathrm{n} / \mathrm{a}$ & 16.00 & 17.00 & 18.00 \\
\hline 2 & $\mathrm{n} / \mathrm{a}$ & 17.00 & 16.00 & 16.00 \\
\hline 3 & $\mathrm{n} / \mathrm{a}$ & 19.00 & 20.00 & 18.00 \\
\hline 4 & $\mathrm{n} / \mathrm{a}$ & 18.00 & 16.00 & 18.00 \\
\hline 5 & $\mathrm{n} / \mathrm{a}$ & 18.00 & 19.00 & 19.00 \\
\hline 6 & $\mathrm{n} / \mathrm{a}$ & 19.00 & 18.00 & 18.00 \\
\hline 7 & 19.00 & 17.00 & 17.00 & 18.00 \\
\hline 8 & 18.00 & 20.00 & 20.00 & 20.00 \\
\hline 9 & 18.00 & 18.00 & 17.00 & 16.00 \\
\hline 10 & 18.00 & 17.00 & 18.00 & 19.00 \\
\hline 11 & 16.00 & 17.00 & 18.00 & 17.00 \\
\hline 12 & 19.00 & 18.00 & 17.00 & 16.00 \\
\hline Minimum & 16.00 & 16.00 & 16.00 & 16.00 \\
\hline Maximum & 19.00 & 20.00 & 20.00 & 20.00 \\
\hline Average & 18.00 & 17.83 & 17.75 & 17.75 \\
\hline
\end{tabular}

Source: calculated by the authors.

The conclusion about the absence of autocorrelation is made in case of exceeding the critical point value, which can be determined from a special table. The value 7.815 corresponds to the critical point for this study with a significance level of 0.05 and three degrees of freedom in the chi-square distribution table.

Since the calculated values of LM-statistics for the S\&P Green Bond Index exceed this critical point, we can conclude for a significance level of $5 \%$ that there is autocorrelation in the green bond market, which indicates its inefficiency even in a weak form. However, we also note the inefficiency of the market for other bonds: the LM statistics values for the S\&P 500 Bond Index are also above the critical point.

Further, the indicators were calculated, allowing to judge the presence of calendar effects (see tables 3 and 4).

Table 3. Dynamics of the S\&P Green Bond Index from July 31, 2014 to December 31, 2018

\begin{tabular}{|c|c|c|c|}
\hline \multirow{2}{*}{$\begin{array}{c}\text { Day of the } \\
\text { week }\end{array}$} & \multirow{2}{*}{$\begin{array}{c}\text { The ratio of the average change in the index during } \\
\text { the day of the week to the average daily change in } \\
\text { the index over the period }\end{array}$} & $\begin{array}{c}\text { The proportion of } \\
\text { days during which } \\
\text { the index }\end{array}$ \\
\cline { 3 - 5 } & $\begin{array}{c}\text { fell, } \\
\%\end{array}$ & rose, \% \\
\hline Monday & 1.0002 & 45.85 & 51.53 \\
\hline Tuesday & 0.9999 & 51.53 & 47.60 \\
\hline Wednesday & 1.0001 & 49.57 & 50.00 \\
\hline Thursday & 1.0001 & 50.00 & 49.13 \\
\hline Friday & 1.0002 & 52.40 & 46.29 \\
\hline Saturday & - & - & - \\
\hline Sunday & - & - & - \\
\hline
\end{tabular}

Based on the data presented, it is clear that the «effect of the day of the week» and «the effect of the end of the week» are not observed in the green bond market. Monday profitability exceeds other days. The smallest yield and most frequent decrease in the index is observed on Tuesday, however, deviations from other days are so insignificant that it is premature to talk about any pattern at this stage of the study. Index decline is often 
observed on Friday. The «effect of the day of the week» is also not observed for other bonds, but we can note the presence of a weak «the effect of the end of the week».

Table 4. The dynamics of the S\&P 500 Bond Index from July 8, 2015 to December 31, 2018

\begin{tabular}{|c|c|c|c|}
\hline \multirow{2}{*}{$\begin{array}{c}\text { Day of the } \\
\text { week }\end{array}$} & \multirow{2}{*}{$\begin{array}{c}\text { The ratio of the average change in the index } \\
\text { during the day of the week to the average } \\
\text { daily change in the index over the period }\end{array}$} & \multicolumn{2}{|c|}{$\begin{array}{c}\text { The proportion of } \\
\text { days during which } \\
\text { the index }\end{array}$} \\
\cline { 3 - 5 } & & $\begin{array}{c}\text { fell, } \\
\%\end{array}$ & rose, $\%$ \\
\hline Monday & 1.0003 & 44.65 & 54.09 \\
\hline Tuesday & 1.0000 & 48.04 & 51.40 \\
\hline Wednesday & 0.9999 & 50.28 & 49.72 \\
\hline Thursday & 1.0000 & 43.82 & 56.18 \\
\hline Friday & 1.0002 & 41.48 & 57.39 \\
\hline Saturday & - & - & - \\
\hline Sunday & - & - & - \\
\hline
\end{tabular}

Among the remaining months, January took 11 th, 4th, 5th and 1st place, respectively, in 2015-2018, according to the monthly growth of the S\&P Green Bond Index. For the S\&P 500 Bond Index -8 th, 10th and 9th place in 2016-2018. Consequently, the presence of the «January effect» is slightly more pronounced for green bonds, but cannot be confirmed in any of the markets under consideration.

Thus, the results of the study show that within the framework of the considered concept, the green bond market is ineffective even to a small extent in terms of the completeness of the information contained in the prices. However, it is also worth noting the inefficiency of the market for non-green bonds. Thus, the inefficiency of the green bond market cannot be regarded as an obstacle to investing, despite the fact that the hypothesis of a greater efficiency of the green bond market due to their independent external assessment and disclosure of information on the use of collected funds cannot be considered confirmed.

\section{Discussion}

Effective work of the green bond market and, accordingly, economically sound quotes will allow to successfully attract financing for projects in the field of green energetic. If financial fraud and stock bubbles occur in the market, the number of investors will decrease, and the amounts accumulated by issuers will not correspond to their needs and performance.

The calculations showed that the green bond market is not effective even in a weak form at the moment. This is consistent with the conclusions drawn from other segments of the stock exchanges $([3-4,6])$. At the same time, this study confirms: the classic calendar effects, massively manifested in the middle of the 20th century, are not typical for green bonds and for most other securities [7]. Since a literature review showed that unique effects [12-14] are observed in some segments of the exchange, it can be assumed that the formation of the green bond market and the availability of quotation information over a longer period will also highlight its unique calendar effects.

To increase the sustainability of the green bond market, the supply and demand for them and, accordingly, the development of the green economy, it is necessary to increase the rationality of potential investors in green bonds when analyzing information about them (great knowledge about a clean economy, resource-saving technologies, etc.), improving models the market (high-quality work of financial analysts by expanding their number and, consequently, competition, special education), reducing transaction costs and increasing the density of information ionic environment (distribution of reports on the green bond market, 
dynamics of their indices, etc.). Also, the standardization of the concepts used and the expansion of the number of investors, especially qualified institutional ones, which strengthen confidence in the market and shape trade trends, will contribute to increasing the efficiency of the market.

The analysis of the state of the green bond market in the Russian Federation allows us to make the following recommendations for its development:

1) In order to increase the number of issuers of green bonds, federal and regional ministries of economic development and energy, development corporations, entrepreneurship support centers and business incubators need to provide full information on the benefits of green bonds (tangible - attracting financing, and intangible - improving reputation, etc.) to organizations working in the energetic sector to provide technical and consulting support for their release.

Currently, companies can receive a subsidy for reimbursement of coupon income costs to popularize green bonds in the Russian Federation, if the purpose of obtaining financing is to introduce the best available technologies. The reimbursement amount for projects involving the purchase of domestic industrial equipment is up to $90 \%$, for other projects up to $70 \%$. But there is a limit to the total cost of the issue - it should not be more than 30 billion rubles.

In addition to this, we can offer, on a competitive basis, to pay for services on an external independent evaluation of a bond loan for marking bonds as green. Knowledge of companies operating in the territory of the subject will help to make this competition effective. Currently, some issuers are focused on green purposes, but do not label their securities accordingly.

Issuers that implement the most significant projects should receive guarantees and sureties from business support organizations, state and municipal guarantees.

For example, JSC «Federal Corporation for the Development of Small and Medium Enterprises» issues guarantees and sureties for exchange-traded bonds. Emphasis in this direction can be placed specifically on green bonds to implement the principles of sustainable development. This will increase investor confidence.

2) In order to increase the demand for green bonds, it is necessary to increase the financial literacy of institutional and private investors with potential free cash in relation to green bonds. Bank deposit rates are currently low, and alternative methods of preserving and increasing capital are of particular interest. Green bond prices will slightly correlate with stock asset prices [21] in the Russian Federation and other countries, and green bond loans for existing exchange investors will become an instrument for risk diversification. An additional external evaluation of bond issues can reduce the risk of investing in green bonds compared to other. In addition, the purchase of green bonds for institutional investors and for their issuers may lead to an improvement in reputation.

Encouraging private investors to purchase green bonds is possible by exempting them from personal income tax on income received from trading operations with these bonds. A similar norm is currently valid for securities of the high-tech (innovation) sector.

You can even fix the minimum share of investing in green bonds at the state level by, for example, private pension funds.

3) For the positive dynamics of the demand and supply of green bonds, it is necessary to develop the country's financial market (providing access to the exchange, transparency of its work, etc.), as well as improving the environmental literacy of the population, understanding the importance of projects in the field of renewable energy sources.

4) It is advisable to calculate the index of circulating green bonds as part of the further development of the sustainable development sector of the Moscow Exchange. Investors will be able to assess the risks of acquiring these securities, and authorities will be able to obtain additional information about their circulation. 
The instruments and development directions of the Russian green bond market partially overlap with general measures to improve the efficiency of such markets. In particular, we are talking about environmental literacy of the population and expanding knowledge about the green economy, disseminating information about the functioning of the market.

Rechecking the effectiveness of the green bond market and determining for it the presence of unique calendar effects is possible in the framework of further research, after the formation of the market and obtaining data for a longer period. An analysis of the Russian green bond market is planned according to the developed methodology: since the first Russian bonds were issued in December 2018, and the green bonds of only two issuers were quoted at the end of 2019 on the Moscow Exchange, so talking about any patterns is premature.

In addition, it is worth continuing to work on improving regulatory instruments and developing the green bond market, taking into account constantly changing external market factors.

\section{Conclusions}

The transition to a green economy, in particular, the construction and operation of power plants based on renewable energy sources, will not only solve the problem of energy deficiency in the regions, but also improve the quality of their environment, lead to lower economic costs in the production of products and services, and save incomes. Thus, energy and economic regional security will be achieved [23].

The implementation of capital-intensive projects in the field of green economy is possible with the help of green bonds. Currently, the green bond market in the Russian Federation is in its infancy, however, the instruments and directions of its development proposed as part of the study will make it possible to successfully finance the green economy.

At the same time, it is necessary to reduce transaction costs in the market and increase the density of its information environment, taking into account the current low efficiency of the green bond market in the Russian Federation and in other countries of the world.

The reported study was funded by RFBR, project number 20-310-70005.

\section{References}

1. Green Bond Principles. Voluntary Process Guidelines for Issuing Green Bonds. (2018). https://www.icmagroup.org/green-social-and-sustainability-bonds/green-bondprinciples-gbp.

2. Green bonds: The state of the market https://www.climatebonds.net/files/reports/cbi_gbm_final_032019_web.pdf.

3. A.G. Ţiţan, Procedia Econ. Financ., 32, $442-449$ (2015). DOI: https://doi.org/10.1016/S2212-5671(15)01416-1

4. V. Karadžic, T.B. Vulic, Economic Annals, 56(191), 107-122 (2011). DOI: 10.2298/EKA1191107K

5. W.F. Sharpe, G.J. Alexander, J.V. Bailey, Investments (Prentice Hall, Englewood Cliffs, 2008)

6. A. Almail, F. Almudhaf, Econ Bus Lett., 6, 2, 48-53 (2017). DOI: https://doi.org/10.17811/ebl.6.2.2017.48-53 
7. A. Plastun, X. Sibande, R. Gupta, M.E. Wohar, The North American Journal of Economics and Finance, 49, 181-205 (2019). DOI: https://doi.org/10.1016/j.najef.2019.04.011

8. P.K. Narayan, S. Mishra, S. Narayan, QREF, 54, 1, 51-60 (2014). DOI: https://doi.org/10.1016/j.qref.2013.07.008

9. A. Yunita, S.M. Martain, Afr. J. Bus. Manage., 6, 11, 3880-3887 (2012). DOI: https://doi.org/10.5897/AJBM10.1038

10. J.M. Gbeda, J.A. Peprah, IJEF, 42, 4, $727-749$ (2018). DOI: 10.1007/s12197-0179409-7

11. E.V. Ţilică, D. Oprea, Procedia Econ. Financ., 15, 704-710 (2014). DOI: https://doi.org/10.1016/S2212-5671(14)00543-7

12. J. Zhang, Y. Lai, J. Lin, Finance Research Letters, 20, 47-62 (2017). DOI: https://doi.org/10.1016/j.frl.2016.09.006

13. A. Derbali, S. Hallara, Cogent Business and Management, 3, 1 (2016). DOI: https://doi.org/10.1080/23311975.2016.1147111

14. A. Halari, C. Helliar, D.M. Power, N. Tantisantiwong, QREF, 74, 85-96 (2019). DOI: https://doi.org/10.1016/j.qref.2018.05.018

15. L. Zunino, A.F. Bariviera, M.B. Guercio, L.B. Martinez, O.A. Rosso, Physica A, 391, 18, 4342-4349 (2012). DOI: https://doi.org/10.1016/j.physa.2012.04.009

16. S.A. Bhat, Decision, 45, 4, 313-323 (2018). DOI: https://doi.org/10.1007/s40622-0180195-7

17. M.J. Bachelet, L. Becchetti, S. Manfredonia, Sustainability, 11, 4 (2019). DOI: https://doi.org/10.3390/su11041098

18. O.D. Zerbib, JBF, 98, 39-60 (2019). DOI: 10.1016/j.jbankfin.2018.10.012

19. M.P. Baker, D.B. Bergstresser, G. Serafeim, J.A. Wurgler, Financing the Response to Climate Change: The Pricing and Ownership of U.S. Green Bonds, https://www.nber.org/papers/w25194.pdf.

20. M. Chiesa, S. Barua, JSFI, 9, 2, 138-161 (2019). DOI: https://doi.org/10.1080/20430795.2018.1550993

21. J.C. Reboredo, Energy Econ., 74, 38-50 (2018). DOI: https://doi.org/10.1016/j.eneco.2018.05.030

22. E.R. Bezsmertnaya, Ekonomika. Nalogi. Pravo, 12, 5, 61-69 (2019). DOI: 10.26794/1999-849X-2019-12-5-61-69

23. A. Shcherbak, S. Tishkov, V.V. Karginova-Gubinova, E3S Web Conf., Innovative Technologies in Environmental Science and Education (ITESE-2019), 135, 1-9 (2019). DOI: https://doi.org/10.1051/e3sconf/201913503005 